\title{
Flow Injection Determination of Metronidazole through Spectrophotometric Measurement of the Nitrite Ion Produced upon Alkaline Hydrolysis
}

\author{
Simone S. Simões, ${ }^{a}$ Everaldo P. Medeiros, ${ }^{a}$ Edvaldo N. Gaião, ${ }^{a}$ Wellington S. Lyra, ${ }^{a}$ Pablo N. T. Moreira, ${ }^{a}$ \\ Mario C. U. Araújo, ${ }^{*, a}$ Edvan C. Silva a ${ }^{a}$ and Valberes B. Nascimento ${ }^{b}$ \\ ${ }^{a}$ Departamento de Química, CCEN, Universidade Federal da Paraíba, CP 5093, 58051-970 \\ João Pessoa-PB, Brazil \\ ${ }^{b}$ Departamento de Química,Universidade Federal Rural de Pernambuco, Recife-PE, Brazil
}

Um novo método para determinação de metronidazol, baseado no monitoramento espectrométrico do sal de diazônio produzido in-line pelos íons nitrito, liberados numa hidrólise alcalina, foi desenvolvido e aplicado com sucesso a comprimidos $\left(r=0,9993,2,0-20,0 \mathrm{mg} \mathrm{L}^{-1}\right.$, $\mathrm{LD}=0,7 \mathrm{mg} \mathrm{L}^{-1}$ ), sem interferência de ingredientes comumente presentes.

A new method for metronidazole determination, based on spectrometric monitoring of a diazonium salt produced in-line by alkaline hydrolysis released nitrite ions, was developed and successfully applied to pharmaceutical tablets $\left(r=0.9993,2.0-20.0 \mathrm{mg} \mathrm{L}^{-1}, \mathrm{DL}=0.7 \mathrm{mg} \mathrm{L}^{-1}\right)$ with no interference from common ingredients accompanying the drug.

Keywords: flow injection analysis, spectrophotometry, pharmaceuticals, metronidazole, nitrite

\section{Introduction}

Metronidazole (MTZ), 2-(5-nitro-2-methylimidazol-1-yl)ethanol, likewise others nitroimidazole derivatives presents biological activity against anaerobic micro-organisms, being largely used as the active ingredient of antihelminthic medicines. ${ }^{1}$ Thus, there is an important demand for rapid and simple methods for the determination of MTZ in pharmaceutical preparations. Methods based on HPLC and classical volumetric titration are recommended by the pharmacopoeia for the direct determination of MTZ. ${ }^{2}$ Although this later one is kind of simple, being daily practiced in many routine analysis laboratories, it is time consuming and very tedious as it is based on the use of acetic anhydride. Various research studies have been devoted to the development of new high performance alternative methods for determination of the drug in dosage forms using different techniques such as high performance liquid chromatography, ${ }^{3}$ supercritical fluid chromatography, ${ }^{4}$ differential pulse polarography ${ }^{5}$ and voltammetry with glassy carbon electrode ${ }^{6}$ or chemically modified electrodes. ${ }^{7}$ Flow analysis approaches have also being successfully applied on developing fast analytical methods for determination of some antihelmintic

*e-mail: laqa@quimica.ufpb.br and antiprotozoal with spectrometric ${ }^{8-10}$ and biamperometric detection in dosage forms. ${ }^{11}$

The alkaline hydrolysis of MTZ releases the nitro group as nitrite ion and the reaction can be carried out in a quantitative way by controlling the $\mathrm{pH}$, temperature and hydrolysis time. Thus, a simple measurement of the yielded nitrite ions can be used to determine MTZ. This approach has been taken advantage of to implement MTZ analytical procedures. ${ }^{12-14} \mathrm{An}$ assay based on measurement of the change in ultraviolet absorbance during the alkaline hydrolysis of the compound was proposed for determination of MTZ in oral suspensions. ${ }^{12}$ Another one, based on colorimetric monitoring of the diazonium salt produced by a diazotizationcoupling reaction with the released nitrite ions, has long been proposed and optimized later on. ${ }^{13,14}$ Despite the good selectivity and sensitivity of these procedures, they are time consuming and employ large amounts of reagents.

This work describes a flow injection analysis (FIA) approach for determination of MTZ based on the spectrometric monitoring of nitrite ions released from an alkaline hydrolysis pre-treatment of the sample. The method combines the high specificity of the diazotizationcoupling reaction for nitrite ions with advantages inherent to the FIA approaches. A very fast, reliable and low reagent consumption method was developed and applied to the analysis of the drug in tablets. 


\section{Experimental}

The hydrolysis, diazotization and coupling reactions

MTZ releases nitrite ion on hydrolysis with the formation of 2-(2-methylimidazol-1yl)-ethanol. ${ }^{12} \mathrm{~A}$ diazonium ion can be produced by the reaction of the nitrite ion with sulfanilamide. Subsequently, a diazonium salt can be produced by the reaction of the diazonium ion with $\mathrm{N}-(1-$ naphthyl)ethylenediamine dihydrochloride. The whole process (diazotization and coupling reaction) is very fast and can be promptly done by direct mixing the nitrite ion with a mixture of sulfanilamide and $\mathrm{N}$-(1-naphthyl)ethylenediamine dihydrochloride in acid medium. ${ }^{15}$

\section{Reagents and solutions}

All the chemicals were used as received. Pharmaceutical grade MTZ was supplied by Dongyang Pharmaceutical Chemical. N-(1-naphthyl)ethylenediamine dihydrochloride (NED) was from Sigma and sulfanilamide from Mallinckrodt. Other chemicals were from Merck. The solutions were daily prepared with de-ionized water (Mili-Q Plus $18 \mathrm{M} \Omega \mathrm{cm}$ ) and the carrier stream was a $100 \mathrm{mmol} \mathrm{L}^{-1}$ solution of $\mathrm{KH}_{2} \mathrm{PO}_{4}$ $(\mathrm{pH}=7.0)$. The chromogenic reagent was a solution containing $0.03 \mathrm{~mol} \mathrm{~L}^{-1}$ sulfanilamide, $0.002 \mathrm{~mol} \mathrm{~L}^{-1} \mathrm{NED}$ and $0.6 \mathrm{~mol} \mathrm{~L}^{-1} \mathrm{HCl}$. Standard solutions of MTZ (2.0 to 20.0 $\mathrm{mg} \mathrm{L}^{-1}$ ) were prepared by proper dilutions in $0.1 \mathrm{~mol} \mathrm{~L}^{-1}$ $\mathrm{NaOH}$ of a $1000 \mathrm{mg} \mathrm{L}^{-1}$ stock solution of the drug. This later one was also prepared in $0.1 \mathrm{~mol} \mathrm{~L}^{-1} \mathrm{NaOH}$ and standardized.

\section{Sample and sample handling}

The samples were five brands of MTZ tablets purchased from local drugstores. Their trade names and respective drug contents in mg/tablet were Helmizol-250, Basf-400, Flagil-250, Canderm-400 and Genérico-250. A portion of 10 tablets of each one was weighed to acquire the mean weigh (roughly 340 to $600 \mathrm{mg}$ ) and then grinded in a mortar to produce a fine powder. An appropriate amount of the powder (300 to $600 \mathrm{mg}$ ) was dissolved in $50-100 \mathrm{~mL}$ of a $0.1 \mathrm{~mol} \mathrm{~L}^{-1} \mathrm{NaOH}$ solution at room temperature shaking the mixture with a magnetic stirring for 10 minutes and, after filtering for removing insoluble particles, diluted to a final volume of $250 \mathrm{~mL}$ with the same $\mathrm{NaOH}$ solution. Subsequent dilutions, 1:25 and 1:40 - for tablets of 250 and $400 \mathrm{mg}$, respectively, were done to obtain a final concentration of MTZ inside the linear range of the calibration curve. An overnight rest period at room temperature was long enough to guarantee a complete hydrolysis of the MTZ in the samples. The hydrolysis time can be greatly shortened by a heating treatment procedure. ${ }^{14}$

\section{Apparatus}

The FIA assembly includes an eight channel-twelve rolls Gilson peristaltic pump, model Minipuls-3, employing $\mathrm{PVC}^{\circledR}$ pumping tubes and Teflon ${ }^{\circledR}$ line tubes of $1.72 \mathrm{~mm}$ and $0.8 \mathrm{~mm}$ inner diameter, respectively, working at a flow rate of $1.4 \mathrm{~mL} \mathrm{~min}^{-1}$; a $100 \mathrm{MHz} \mathrm{PC}$ equipped with an A/D-D/A PC-LabCard (Advantech) interface card, model PCL-711S; a data acquisition and handling software for Windows written in LabView 5.1; a proportional injector using a sample loop of $180 \mu \mathrm{L} ;{ }^{16}$ a $77 \mathrm{~cm}$ reaction coil and a lab-made photometric detection unit based on LED-phototransistor technology that uses a $2 \mathrm{~mm}$ optical path Hellma-worldwide flow cell with a dead volume of $80 \mu \mathrm{L}$ and a green $\operatorname{LED}\left(\lambda_{\max }=560\right.$ $\mathrm{nm}){ }^{17,18}$ Figure 1 shows a diagram of the FIA system.

Keeping the proportional injector "PI" at the position showed in Figure 1a, the reagent " $R$ " keeps recycling, while the sample " $\mathrm{S}$ " is aspirated to fill the sample loop "L". The injection of the sample in the carrier stream is done by exchanging the position of the PI, Figure $1 \mathrm{~b}$. The designed reaction coil "RC" assures a sufficient color development before the flowing solution reaches the spectrometric flow cell "FC". The solutions are finally collected in the waste disposal device "W". A peristaltic pump (not shown) drives the solutions.

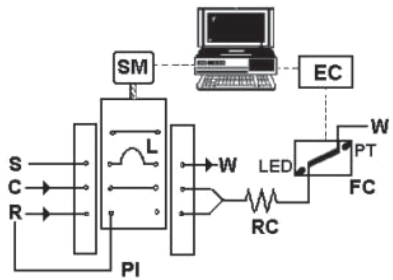

(a)

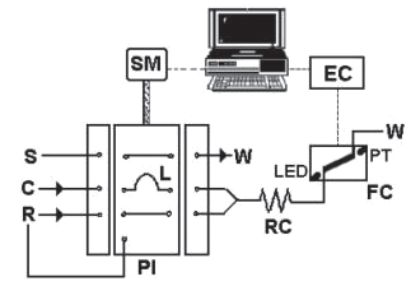

(b)
Figure 1. FIA manifold: SM, step motor; $S, C$ and R, lines of sample, carrier and reagent; L, loop of sample; PI, proportional injector; RC, reaction coil; FC, flow cell; LED, light emitting diode; PT, phototransistor; EC, auxiliary electronic circuit; $W$, waste. The arrows indicate the pumping sites and directions of the fluids. For more details, see text.

\section{FIA procedure}

Both, the carrier and the chromogenic reagent solutions are continuously pumped through the system at a flowing rate of $1.4 \mathrm{~mL} \mathrm{~min}^{-1}$. A sample volume of $180 \mu \mathrm{L}$ (loop of $37 \mathrm{~cm}$ length) is injected in the carrier stream and the transient absorbance uprising is proportional to the analyte concentration. A calibration curve may be used to perform the analysis and the injections can be done every $90 \mathrm{~s}$ at 
room temperature (around $25^{\circ} \mathrm{C}$ ). This time delay could be reduced by accelerating the cell clean up. It could be accomplished by a transitory enhancing of the flow rate to a maximum permitted pumping rate value for a few seconds immediately after the signal acquisition.

\section{Reference method}

A classical titration method recommended by the USP was employed as a reference method. ${ }^{2}$ Briefly, $100 \mathrm{mg}$ of the tablet was dissolved in c.a. $20 \mathrm{~mL}$ of acetic anhydride and, after addition of 2 drops of the appropriate indicator, the MTZ content was titrated with an $\mathrm{HClO}_{4}$ solution. This method was also employed to standardize MTZ stock solutions.

\section{Results and Discussion}

\section{The chemical reactions}

All the reactions involved in the proposed procedure can be carried out satisfactorily at room temperature, but they require very different $\mathrm{pH}$ ranges to be quite effective, ranging from strong alkaline, for the MTZ hydrolysis, to strong acid, for the diazotization and coupling reactions. A neutral phosphate buffer solution was found suitable as a carrier; for it dilutes the sample slowing down its $\mathrm{pH}$ from approximately 13 to around 7 before the sample reaches the strongly acid reagent flow where another strong $\mathrm{pH}$ variation will take place from around 7 to below 1 .

\section{The hydrolysis reaction}

The alkaline hydrolysis of MTZ releases the nitro group as nitrite ion and the reaction can be carried out in a quantitative way under $\mathrm{pH}$-temperature-time controlled conditions. The hydrolysis reaction requires a strong alkaline medium $\left(\mathrm{NaOH} 0.1\right.$ to $\left.4.0 \mathrm{~mol} \mathrm{~L}^{-1}\right)$ and it can be completed in $15 \mathrm{~min}$ to $2 \mathrm{~h}$ if carried out in a boiling water bath. ${ }^{12-14}$ At room temperature the hydrolysis requires several hours to be complete.

A study of the optimum concentration of sodium hydroxide to carry on the targeted quantitative hydrolysis at room temperature revealed it could be complete overnight using a $\mathrm{NaOH} 0.1 \mathrm{~mol} \mathrm{~L}^{-1}$ solution. This condition was then short-listed for all further experiments.

As the MTZ content is very high in the addressed samples and the Griess method is high sensitive to determine nitrite, a complete hydrolysis of MTZ is not really necessary. It simply obviates the need for controlling this step, since it is done in a separate procedure before the nitrite analysis in the FIA system.

\section{The diazotization and coupling reactions}

Diazotization-coupling reactions have been largely used for spectrometric determination of nitrite. ${ }^{19}$ The effectiveness of a chromogenic reagent solution $\left(0.03 \mathrm{~mol} \mathrm{~L}^{-1}\right.$ sulfanilamide and $0.002 \mathrm{~mol} \mathrm{~L}^{-1} \mathrm{NED}$ in $0.6 \mathrm{~mol} \mathrm{~L}^{-1} \mathrm{HCl}$ ) proposed in the literature was examined and showed to be also well suited for the MTZ analysis under the proposed FIA conditions. ${ }^{15}$ The color develops immediately and no interference from by products of the hydrolysis was verified in the nitrite subsequent reactions. Thus, it was not necessary to make any further deep investigation to short-list that chromogenic reagent solution for the intended analysis.

\section{The flow parameters}

It is known that low flow rates can originate small and enlarged peaks due to a high dispersion of the sample. On the other hand, at very high flow rates the reaction may not progress enough to give an adequate signal-to-noise ratio. Obviously, an optimum flow rate will depend on the sample volume and coil length. An optimized value for each variable must be taken to be that resulting in a good compromise among peak high, calibration slope, reproducibility and baseline stability. Although the high MTZ concentration in the target samples obviates the need for a very high sensitive method, an optimum flow rate for a reaction coil of $77 \mathrm{~cm}$ and an injection volume of $180 \mu \mathrm{L}$ was investigated. For the sake of simplicity, flow rates of the carrier solution and the chromogenic reagent solution were kept equal to each other in this study. A

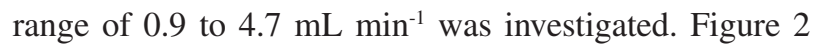
shows that flow rates below $2 \mathrm{~mL} \mathrm{~min}^{-1}$ significantly improve the sensitivity. A flow rate of $1.4 \mathrm{~mL} \mathrm{~min}^{-1}$ gathered an optimum compromise between flow rate, sensitivity and sampling rate.

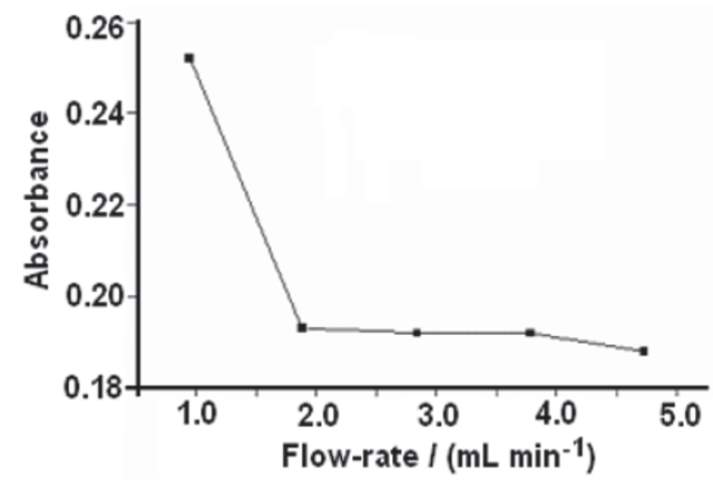

Figure 2. Optimization of the carrier flow rate. 


\section{Typical calibration curve}

Under the above conditions, well shaped transient signals of ca. 90 s were obtained and a plot of the absorbance versus concentration of MTZ was linear $\left(A=0.0196+0.0124 \mathrm{C}\left[\mathrm{mg} \mathrm{L}^{-1}\right], \mathrm{r}=0.9993, \mathrm{n}=10\right)$ over the range $2.0-20.0 \mathrm{mg} \mathrm{L}^{-1}$, with a detection limit of $0.7 \mathrm{mg} \mathrm{L}^{-1}$ (three times the standard deviation). Figure 3 shows a series of transient signals obtained on the construction of the analytical curve. A leveling off (not shown) was observed for higher MTZ concentrations. A relative standard deviation of $1.8 \%$ was estimated from a series of 20 sequential injections of an $11 \mathrm{mg} \mathrm{L}^{-1} \mathrm{MTZ}$.

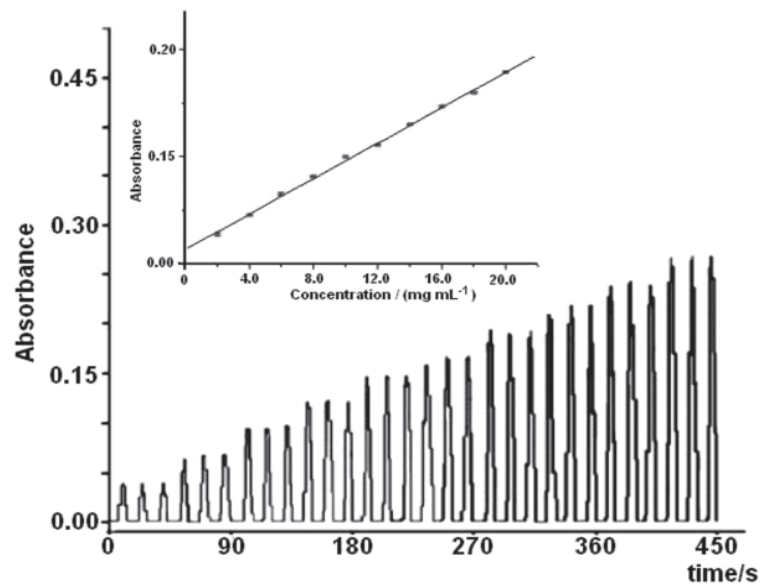

Figure 3. Fiagram of MTZ. Inset displays the resulting analytical curve.

\section{Practical applications}

The method was applied to five brands of MTZ tablets well known in the market. A reference method was employed to validate the proposed one. Table 1 presents a comparison between the methods. For most samples a very close agreement among the two methods was encountered with a relative error smaller than $1 \%$. A paired t-test showed the methods do not give significantly different values under a confident level of $95 \%$. Additionally, these analytical results imply there is no significant interference from the inactive excipient materials commonly accompanying the drug in those formulations (starch, mannitol, cellulose, polyvinylpyrrolidone, calcium phosphate, magnesium stearate, hydroxypropyl-methylcellulose, polyethylene glycol, titanium dioxide) on the analytical response of the proposed method. It was also verified a good agreement between the nominal amount of MTZ in the tablet and the experimental ones.

It should be noted the proposed method is not a stability indicating assay and it lacks selectivity to other nitroimidazole derivatives which could be present as impurities in MTZ formulations, as these nitroimidazole derivatives will also release nitrite anion under alkaline hydrolysis.

\section{Conclusions}

The above experiments have demonstrated the viability of the determination of MTZ in real samples by analyzing the nitrite ions released from an alkaline hydrolysis of the MTZ using a simple flow injection assembly with spectrometric detection. The simplicity, low cost and high sample throughput (40 samples per hour) with good precision (RSD of $1.8 \%, \mathrm{n}=20$ ) and accuracy, ranks the proposed method competitive for routine analysis of the drug in pharmaceutical formulations. If compared to the method recently proposed by our research group, ${ }^{10}$ it has the advantage of being more easily ran. Low consumption and disposal of sample and other chemicals are also advantages of the method, in compliance with the environmental demands. The proposed FIA procedure for determination of MTZ in pharmaceutical tablets is free of interferences from inactive ingredients commonly accompanying the drug in those formulations, being an attractive alternative to the classical reference method. Despite the hydrolysis time is very long for the sample pre-treatment, ranging from $2 \mathrm{~h}$ to an overnight delay, the high sample throughput from the FIA measurements makes the method well advantageous for analysis of large amount of samples. Research studies on diminishing the time delay of that sample pre-treatment is on the way in our laboratory.

Table 1. Amounts of the MTZ in commercial tablets

\begin{tabular}{|c|c|c|c|c|}
\hline Sample & Tablet label content (mg) & Tablet label minimum content (mg) & Reference method (mg) & Proposed method (mg) \\
\hline A & 400 & 360 & 372 & 372 \\
\hline B & 400 & 360 & 361 & 360 \\
\hline $\mathrm{C}$ & 250 & 225 & 236 & 238 \\
\hline $\mathrm{D}$ & 250 & 225 & 256 & 245 \\
\hline E & 250 & 225 & 244 & 245 \\
\hline
\end{tabular}




\section{Acknowledgments}

M.C.U. Araujo and V.B Nacimento gratefully acknowledge the support by $\mathrm{CNPq}-$ Brazil (Proc. $\mathrm{N}^{\circ}$ : 478961/2001-4 and 470535/2001-6, respectively). S. S. Simões, E. P. Medeiros, E. N. Gaião, W. S. Lyra, P. N. T. Moreira, M .C. U. Araujo is honoured with CNPq scholarship.

\section{References}

1. Edwards, D. I.; J. Antimicrob. Chemother. 1993, 31, 9.

2. United States Pharmacopoeia 25, NF 20, RockVille, 2002, p.1147.

3. Akay, C.; Ozkan, S. A.; Senturk, Z.; Cevheroglu, S.; Farmaco 2002, 57, 953 .

4. Bari, V. R.; Dhorda; U. J.; Sundaresan, M.; Anal. Chim. Acta, 1998, 376, 221.

5. La-Scalea, M. A.; Serrano, S. H. P.; Gutz, I. G. R.; J. Braz. Chem. Soc. 1999, 10, 127.

6. Ozkan, S. A.; Ozkan, Y.; Senturk, Z.; J. Pharm. Biom. Anal. 1998, 16, 801.

7. Brett, A. M. O.; Serrano, S. H. P.; Gutz, I.; LaScalea, M. A.; Bioelectrochem. Bioenerg. 1997, 42, 175.
8. Mohamed, M. Y.; ElGendy, A. Y.; ElBardicy, M. G.; Tawakkol, M. S.; Ahmad, A. K. S.; Spectrosc. Lett., 1996, 29, 299.

9. Elgizawy, S. M.; Anal. Lett., 1995, 28, 83.

10. Medeiros, E. P.; Nascimento, E. C. L; Medeiros A. C. D.; Veras Neto, J. G.; Silva, E. C.; Araújo, M. C. U.; Anal. Chim. Acta, 2004, 511, 113.

11. Palomeque, M.; Bautista, J. A. G.; Mateo, J. V. G.; Calatayude, J. M.; Anal. Chim. Acta, 1999, 401, 229.

12. Sanyal, A. K.; Analyst, 1992, 117, 93.

13. Lau, E. P. K.; Yao, C.; Lewis, M.; Senkowski, B. Z.; J. Pharm. Sci. 1969, 58, 55.

14. Sanyal, A.K.; J. Ass. Off. Anal. Chem. 1988, 71, 849.

15. Motomizu, S.; Sanada, M.; Anal. Chim. Acta 1995, 308, 406.

16. Pasquini, C.; Raimundo, I. M.; Analyst 1997, 122, 1039.

17. Gaião, E. N.; Honorato, R. S., Santos, S. R. B.; Araújo, M. C. U.; Analyst 1999, 124, 1727.

18. Santos, S. R. B.; Araújo, M. C. U.; Honorato, R. S.; Zagatto, E. A. G.; Lima, J. L. F. C.; Lapa, R. A. S.; J. Autom. Methods Manage. Chem. 2000, 22, 83.

19. Sreekumar, N. V.; Narayana, B.; Hegde, P.; Manjunatha, B. R.; Sarojini, B. K.; Microchem. J. 2003, 74, 27.

Received: July 19, 2005 Published on the web: April 12, 2006 